\title{
Estudos sobre imigrantes e fontes orais: identidade e diversidade*
}

\author{
Regina Weber**
}

\section{Imigração e identidade}

No texto que segue, pretendo inicialmente questionar representações da categoria "imigrante", apontando para a diversidade de grupos denominados por esse termo, principalmente quando há um enquadramento na problemática da etnicidade. Num segundo momento, abordo como a história oral pode contribuir para os estudos de identidade e, por fim, destaco alguns aspectos da pesquisa por meio de entrevistas dentro da temática reconhecida como "imigração".

É uma tarefa árdua falar de imigrantes, no sentido plural, sob o enfoque da etnicidade, uma vez que se trata de grupos muito variados. Exemplificando com o caso do Rio Grande do Sul, grosso modo, pode-se afirmar que são sete os grupos étnicos derivados de processo imigratório em maior escala: em ordem alfabética, açoriano-portugueses; alemães, espanhóis, italianos, judeus, poloneses, sírio-libaneses; mas também, como indicam algumas pesquisas antigas ou em desenvolvimento, podemos acrescentar russo-ucranianos, franceses, japoneses, palestinos, pomeranos e outros grupos que são segmentações desses grupos maiores, como é o caso dos galegos. Os processos de "etnogênese",

* Uma versão preliminar deste texto foi apresentada na mesa redonda Diversidade étnica e fontes orais, no XI Encontro Nacional de História Oral, realizado no Rio de Janeiro em julho de 2012.

** Professora no Departamento de História e no Programa de Pós-Graduação da História da Universidade Federal do Rio Grande do Sul (UFRGS). 
"segmentação" e "englobamento", fenômenos reconhecidos pela moderna teoria da etnicidade, ${ }^{1}$ também observáveis em grupos nativos ou afrodescendentes, são em número bastante elevado no que tange a imigrantes, devido à crescente multiplicação dos Estados-nações que embasam as identidades de imigrantes pelo menos desde o século XIX. ${ }^{2}$ Contemporaneamente, a reconhecida diferenciação entre pesquisas sobre imigrantes e pesquisas sobre grupos nativos e africanos tende a ser matizada, pois já existem estudos sobre emigrações contemporâneas de africanos, identificados pelo país de origem, e de latino-americanos, os quais, a par de uma identidade nacional, podem constituir uma corrente regional com forte vinculação a um grupo descendente de nativos. Mais frequentes nos campos da sociologia, antropologia e ciências sociais aplicadas (comunicação, turismo, assistência social), já existem dissertações e teses sobre tais grupos concluídas em programas de pós-graduação em história, muitas delas possibilitadas, justamente, pelo recurso à história oral, como as dissertações de mestrado defendidas na Pontifícia Universidade Católica de São Paulo (PUC-SP), uma sobre imigração argentina em São Paulo (Domingues, 2004) e outra sobre identidades de angolanos imigrados para o Pará (Guedes, 2005).

Em termos de imigração, é preciso considerar três possibilidades: as imigrações mais antigas, cujo protótipo são as imigrações por levas, concentradas no século XIX - que, por sua vez, alimentaram novas correntes migratórias no século posterior; as imigraçóes contemporâneas; e uma terceira possibilidade que, num sentido restrito do termo, não constitui imigração, pois se relaciona aos descendentes de imigrantes, muitas vezes de gerações distanciadas dos antepassados da primeira geração. Quanto ao contexto histórico e fontes de pesquisa há diferença entre essas três alternativas; entretanto, em termos de teorizações e interpretações é possível haver análises que as perpassem. Para ampliar seu alcance no tempo, operando como estudo de "tradição oral”, a história oral depende de grupos familiares com estratégias memoriais nem sempre localizadas pelo historiador. $\mathrm{O}$ mais frequente é a pesquisa sobre acontecimentos vivenciados pelos entrevistados, ou seja, a história oral tem sido empregada principalmente para estudar os novos imigrantes e os

1 Para uma visão do campo dos referenciais teóricos da etnicidade, ver Poutignat; Streiff-Fenart (1998) e Fenton (2003). Tais discussões teóricas desenvolveram-se inicialmente, como é conhecido, no campo da antropologia e da sociologia.

2 Sobre a "universalização do fato nacional" e a imigração como "fato nacional", ver Sayad (1998, p. 266). 
descendentes. Entretanto, publicações e eventos acadêmicos usualmente não fazem distinção entre estes e os imigrantes mais antigos, pesquisados com fontes documentais, seriais ou não.

Esse modo de ver (ou representar) a realidade por parte dos intelectuais é ancorado no modo como os próprios membros dos grupos estudados se veem, ${ }^{3}$ pois essa indistinção, entre descendentes de imigrantes e o grupo de imigrantes do qual são egressos, decorre da manutenção de fronteiras mais ou menos claras entre o grupo e seu entorno, seja: 1) pela ocupação de determinados espaços residenciais e profissionais; 2) pela forma como os outros grupos os rotulam; 3) pelo incentivo aos casamentos intraétnicos; 4) pela manutenção de sinais simbólicos e rituais de pertencimento étnico; 5) pela “institucionalização" de manifestações étnicas em festividades cíclicas, jornais, escolas, igrejas, associações recreativas e operárias - práticas que garantem grande visibilidade ao grupo, tanto aos próprios membros, quanto aos não membros, e permitem fontes escritas para a pesquisa desses imigrantes. Vejamos alguns casos específicos de objetivação ${ }^{4}$ de fronteiras culturais, seja pelo próprio grupo, seja pelo modo como é visto pelo olhar externo:

Hoje em dia, adentrando no município de Nova Trento, destacam-se de súbito a imagem de Santa Paulina e as cores verde, branca e vermelha pintadas nos postes da rede elétrica a meio metro, representando, desta maneira, a bandeira italiana, e simbolizando que a cidade, se assim pode-se dizer, dá visibilidade àquela cultura. $\mathrm{E}$ vem-se reforçando essa italianidade, própria a Nova Trento, na imagem da primeira santa brasileira que "jamais perdeu o sotaque estrangeiro", vinda da Itália como um farol aceso para a religiosidade e a economia da cidade (Nascimento, 2006, p. 49; pesquisa sobre imigrantes italianos que se instalaram em um município de Santa Catarina).

Os japoneses eram considerados um perigo nacional também pelo seu padrão de comportamento e sua forma de organização. Seus valores culturais provocavam estranhamentos e foram utilizados, no discurso, como elementos inibidores à sua integração à sociedade. Seus hábitos, como a

3 Em linguagem teórica, diríamos se tratar de uma endodefinição (Poutignat; Streiff-Fenart, 1998, p. 147).

4 Esta noção está sendo empregada com um sentido semelhante ao de "estruturas sociais incorporadas" (Bourdieu, 2007, p. 435). 
maneira de se vestir e alimentar, foram destacados como fatores de distanciamento social (Wawzyniak, 2004, p. 107; pesquisa sobre imigrantes japoneses que se instalaram no Paraná).

A comunidade imigrante, com o objetivo de conservar e estreitar vínculos sociais entre seus membros, manteve a prática de visitas periódicas. Em seus depoimentos, as narradoras destacaram que estas visitas ocorriam mesmo quando algumas famílias se localizavam em outras cidades, quando, então, o encontro se transformava em uma festa. [...] $\mathrm{Na}$ verdade, estas visitas desempenharam um papel importante nos arranjos dos futuros casamentos (Pereira, 2008, p. 150; pesquisa sobre um grupo de famílias de uma aldeia da região de Toscana, na Itália, que emigraram para o Brasil).

Dentro de todo esse ritualismo da morte, um objeto de extrema importância era o caixão. $\mathrm{O}$ ataúde, nas comunidades polonesas, era de confecção doméstica, de madeira, pregado e forrado com tecidos. Raros eram os ataúdes pintados. Em cada linha existia um colono que se dedicava à produção de caixões (Wenczenovicz, 2007, p. 225; pesquisa sobre poloneses que se instalaram no norte do Rio Grande do Sul).

Todas essas manifestações constituem marcadores de identificação e práticas de memória, que indicam aos indivíduos o sentido de pertencimento ao grupo. Para a história oral, um fenômeno muito importante é o da transmissão da memória intergeracional, que faz daqueles que ouviram os relatos vívidos das testemunhas diretas, muitas vezes de modo repetido, informantes privilegiados, portadores daquilo que Halbwachs (2006) denomina "memória coletiva”. Essa memória familiar é reforçada pela manutenção de objetos dos antepassados que, assim como as lembranças orais, são repassados às novas gerações: "E pelo fato destas caixinhas conservarem objetos que permitem a evocação de experiências e histórias vividas por suas proprietárias, e também por membros do grupo imigrante, elas foram consideradas como 'lugares de memória”" (Pereira, 2008, p. 121). Ou seja, os descendentes de imigrantes, com seus depoimentos, podem alongar no tempo o alcance dos estudos sobre identidade social.

Uma segunda razão para o enquadramento de descendentes como se "imigrantes" fossem pode ser atribuída àquilo que a crítica denomina "naturalização" da condição original do indivíduo e dos grupos, como se houvessem 
características "primordiais" que se mantivessem ao longo do tempo e em diferentes contextos. Nos tempos atuais, quando as identidades de origem são, via de regra, identidades "nacionais", essa identidade que se presume perene e imutável teria sido adquirida pelos indivíduos e grupos em seu país natal.É compreensível que os grupos se vejam dessa maneira, pois é assim que opera a identificação que vincula os indivíduos aos grupos, e não poderíamos estudá-los se assim não fosse. ${ }^{5}$ Quanto a autores de estudos acadêmicos - dos quais se esperam análises de representações - que endossam visões laudatórias e essencializantes de grupos imigrantes ou, no extremo oposto, se ocupam de desmitificá-las, já existe crítica historiográfica consistente sobre o assunto. A menção, neste artigo, a "espanhóis", "poloneses”, “alemães” e outros não se fundamenta nem no registro oficial em passaportes e alfândegas, nem na presunção de que há permanência de uma origem "essencial". A indistinção entre a primeira geração de imigrantes e as posteriores se baseia na ideia, referida acima, da presença de "fronteiras", simbólicas e sociais, entre os grupos em contexto de relações interétnicas.

$\mathrm{O}$ aparato conceitual que está sendo empregado (fronteiras, pertencimento) é resultado da contribuição que as teorizações da etnicidade têm propiciado ao campo dos estudos da imigração, conduzindo a história a um diálogo com outras disciplinas de ciências humanas, desdobramento do qual citamos dois exemplos: a linha de pesquisa que abrange o assunto na Universidade do Vale do Rio dos Sinos (Unisinos) denomina-se Migraçóes, territórios e grupos étnicos; e a avaliação da produção acadêmica acerca da temática no período de 35 anos de existência do PPGH da Universidade Federal de Santa Catarina (UFSC) é denominada pelos autores de Imigração e cultura étnica em Santa Catarina (Oliveira; Klug, 2011). Essas denominações buscam dar visibilidade às novas preocupações dos pesquisadores da temática da imigração. É justamente nesse contexto de discussões renovadas que a história oral pode dar sua contribuição aos estudos de imigração. Se, por um lado, pesquisas que empregam a metodologia da história oral, isto é, que tratam de situações mais recentes, podem se beneficiar de interpretações ou formulações teóricas elaboradas para o estudo de contextos históricos já distanciados no tempo, por outro, a história oral é um meio de investigação privilegiado

5 "Assim, a ênfase no que foi denominado como "construtivismo" na sociologia da etnicidade não é mais do que a boa aplicação de um teorema sociológico padrão: o que é visto como natural pelos atores é entendido pelos sociólogos como socialmente construído" (Fenton, 2003, p. 109). 
para analisar um fenômeno que nem sempre é de fácil apreensão: a vinculação a uma identidade de grupo por parte do indivíduo.

Um tema pode ser estudado através de diferentes fontes; entretanto, a natureza da fonte tende a direcionar a problemática da pesquisa - além da conhecida diferença entre fontes quantitativas e qualitativas, há que se considerar as variações que se encontram no conjunto destas últimas. Por exemplo, usando documentos de uma entidade, tais como atas e registros de sócios de uma associação de imigrantes, teremos em mãos dados - qualitativos sobre modos de organização étnica, lideranças, festividades; porém, via de regra, poucas informações sobre facetas da vida cotidiana nas quais a vinculação étnica tem um papel importante. Por sua vez, "documentos pessoais", que incluem "gravação de memórias de vida narradas pelos próprios protagonistas, as suas velhas fotografias familiares e, sobretudo, as cartas cruzadas entre os membros do grupo doméstico de ambos os lados do mar" (Soutelo Vázquez, 1998, p. 101) $)^{6}$, podem contribuir com outros enfoques do processo imigratório.

Além de possibilitar melhor compreensão do "papel desempenhado pelos imigrantes retornados na mobilização sociopolítica das sociedades de partida", tema de pesquisa do autor mencionado, os documentos pessoais oferecem novas perspectivas do funcionamento concreto das redes relacionais tecidas pela amizade e pela solidariedade étnica, conhecidas como "cadeias migratórias", e dos problemas de inserção social, profissional e cultural nos países de destino (Soutelo Vázquez, 1998, p. 101). A história oral, portanto, partilharia com outros documentos pessoais a virtude de ser benéfica aos estudos de migração, destacando-se, da enumeração de Soutelo Vázquez, sua contribuição ao estudo do agregamento étnico. A condição "étnica” existe, bem entendido, quando os emigrados já se encontram na América, mas as ações que fomentam a união entre esses indivíduos operam desde a sociedade de origem.

É afirmação recorrente que a história oral possibilita acessar vivências de 1) indivíduos comuns, que não deixam registros de outros modos; ou, 2) mesmo se tratando de líderes e pessoas de destaque, de aspectos pouco formalizados da experiência do indivíduo. No campo de estudos de imigração, vários são os assuntos que têm se beneficiado das pesquisas com depoimentos:

6 O artigo citado é fruto das pesquisas do autor sobre imigração galega para a América em conjunto com outros historiadores, vinculados à Universidade de Santiago de Compostela. 
razões, do ponto de vista pessoal e familiar, da emigração; informações disponíveis sobre países de destino e mediações burocráticas; papel da rede de emigrados na sociedade de destino; envolvimento com formas institucionalizadas (associações, jornais, festividades) do grupo de origem; inserção na sociedade de acolhida; relação das gerações nascidas na nova terra com a identidade de "imigrante"; revitalização de identidades em gerações posteriores etc.

O emprego de documentos pessoais e da história oral em estudos de imigração não é propriamente uma novidade, ainda que em décadas anteriores tenha sido feito de modo um tanto amador. ${ }^{7}$ Esse modo de fazer história - que atualmente recebe, via de regra, a denominação de "memorialista" continua ativo, e sempre fornece dados que não devem ser desprezados pelo historiador de perfil mais acadêmico. É certo que, para a pesquisa dos temas acima elencados, o recurso às noções da "etnicidade", conjugado à metodologia da interpelação dos próprios agentes, tem sido bastante profícuo. É o que se busca mostrar na segunda parte desta exposição, resultado da consulta a anais de eventos de história e da busca de teses e dissertações produzidas em programas de pós-graduação em história, em programas que contam com historiadores em seu corpo docente, como os da educação ou aqueles conhecidos como "interdisciplinares".

\section{Estudos sobre imigrantes e história oral}

Abordar a questão da imigração do ponto de vista do uso de depoimentos pode ser feito de inúmeros modos. A opção de não fazer nenhum recorte regional, por grupo imigrante ou por instituição de concentração de pesquisas pode, por um lado, levar a uma análise muito panorâmica; por outro, porém, a análise fica mais matizada pela referência à multiplicidade de grupos

7 Edmundo Gardolinski, filho de imigrantes camponeses poloneses, produziu na década de 1950 um artigo (Gardolinski, 1956) - para o qual ouviu e observou membros desse grupo - que ainda é referência para aqueles que pesquisam a imigração polonesa para o Rio Grande do Sul.

8 Para citar um exemplo, a dissertação de Carla Thoen, defendida no Mestrado em Educação da Universidade de Caxias do Sul, ao operar com a metodologia da história oral e com os referenciais da história cultural, propõe-se a compreender as "representações construídas pelos entrevistados na contemporaneidade" e "a possibilidade de constituição de uma memória coletiva, partindo de um conjunto de memórias" (Thoen, 2011, p. 21). 
presentes no país e porque permite uma visão de onde estão sendo produzidos tais estudos. ${ }^{9}$ Considerando que neste artigo deu-se preferência a estudos de historiadores, há um recorte implícito que deixa de lado pesquisas de sociólogos e antropólogos, os quais - observe-se - possuem uma experiência mais ampla em estudos das imigrações contemporâneas. Ainda que os limites entre esses campos tenham se tornado permeáveis, particularmente pelo uso de referenciais comuns, ${ }^{10}$ são mais frequentes entre historiadores textos descritivos ou que abarquem longos períodos. ${ }^{11}$ Após observar algumas peculiaridades dos estudos mais recentes, abordo a presença da história oral nas grandes áreas e em campos mais específicos da produção historiográfica.

Parte das conclusões que seguem são baseadas em um levantamento de mais de oitenta teses e dissertações registradas no Banco de Teses da Capes e disponibilizadas em bibliotecas digitais universitárias. Como todo levantamento, este tem um índice de aleatoriedade, já que depende da eficiência da burocracia acadêmica em registrar os trabalhos concluídos, tem o viés dos verbetes escolhidos para triagem e desconhece teses produzidas fora do país ou pesquisas realizadas após o doutoramento.

As pesquisas contemporâneas sobre imigração dão a conhecer uma multiplicidade de grupos. Nem todos esses estudos empregam a metodologia da história oral, mas esta, seguramente, tem contribuído para apontar a diversidade e, também, para estabelecer um campo de interlocução, especialmente quando associada às discussões sobre identidade e representações. Além dos grupos sobre os quais já existia expressiva produção bibliográfica e até mesmo congressos específicos (alemães, italianos, poloneses, judeus) ${ }^{12}$, intensifica-se

9 Quando existem textos de discussão historiográfica, a tarefa fica bastante atenuada; todavia, estes são poucos comuns. A coletânea relativa aos 35 anos do Programa de Pós-Graduação em História da Universidade Federal de Santa Catarina elenca várias pesquisas cujos personagens principais são imigrantes, ainda que não tratem especificamente de pesquisas com história oral (Moretto; Nodari, 2011; Oliveira; Klug, 2011).

10 O manual Teorias da etnicidade (Poutignat; Streiff-Fenart, 1998), que tem sido usado como referencial de historiadores, pode ser associado às pesquisas de sociólogos franceses sobre as migrações de populaçôes africanas mediterrâneas para a Europa.

11 A tese de Sarmiento da Silva (2006) sobre a imigração galega acompanha o grupo por mais de cem anos, reunindo farta e diversificada documentação, e a tese de Gattaz (2001) narra a imigração libanesa para o Brasil desde as duas últimas décadas do século XIX até o final do século XX.

12 Tomando-se o caso específico do Rio Grande do Sul, a historiografia da imigração espanhola e polonesa é menos expressiva que a judaica, e a portuguesa só tem destaque pelos estudos sobre açorianos. As publicações sobre alemães e italianos apresentam números geometricamente maiores que os que abordam qualquer outro grupo. 
a produção sobre japoneses, libaneses e outros grupos árabes, ampliam-se os estudos sobre subgrupos (pomeranos, galegos, ucranianos), e, acompanhando o maior movimento de populações entre fronteiras vizinhas, fazem-se mais presentes os estudos sobre grupos latino-americanos.

Outro aspecto importante é a ampliação, com relação aos estudos de imigração mais antigos, de trabalhos acadêmicos sobre a imigração em outros estados além de Rio Grande do Sul, Santa Catarina, Paraná, São Paulo e Rio de Janeiro, do que são exemplos as pesquisas sobre sírio-libaneses (Silva, 2006), italianos (Pereira, 2010) e espanhóis (Alencar, 2009) em Minas Gerais; sobre japoneses (Silva, 2004) e árabes (Fernandes, 2010) no Mato Grosso; sobre italianos em uma cidade da Bahia (Di Gregorio, 2001). Nessas áreas de ocupação mais recente, a imagem de "pioneiro", muito presente entre os colonos alemães e italianos do sul do Brasil desde o século passado, aparece, nos anos 1950, em relatos de imigrantes japoneses que se instalaram no norte do Mato Grosso (Silva, 2004, p. 111). A criação de cursos de pós-graduação em alguns desses estados também estimulou o conhecimento sobre a imigração para essas regiões. No mestrado do Programa de Pós-Graduação em História da Universidade Federal do Mato Grosso, cujas atividades, centradas na temática História, territórios e fronteiras, iniciaram em 1999, foram produzidas a dissertação sobre japoneses acima mencionada e outra sobre sírio-libaneses que se instalaram como comerciantes em Rondonópolis (Rego, 2006). No recente Programa de Pós-Graduação em História Social da Amazônia (Universidade Federal do Pará), cujas atividades iniciaram-se em 2004, foi realizado um estudo sobre os japoneses que constituíram uma comunidade no Baixo Amazonas paraense (Ishizu, 2007).

Entretanto, o levantamento de teses e dissertações que se utilizam da metodologia de história oral em pesquisas de imigração indica a permanência de um maior número de trabalhos sobre imigrantes que se instalaram nos estados do sul e sudeste do país. As instituições cujos programas de pós-graduação em história mais titulam estudantes que operam com a metodologia de história oral são a PUC-SP, com visível predomínio, a Universidade de São Paulo, a Pontifícia Universidade Católica do Rio Grande do Sul, a Universidade Federal do Paraná, a Universidade Federal de Santa Catarina e a Universidade Federal Fluminense. Acadêmicos dos cinco estados do sul-sudeste, portanto, continuam a nortear estudos sobre a temática da imigração, com destaque para São Paulo e Rio Grande do Sul se tomarmos o 
conjunto de instituições universitárias desses estados que abrem espaço para estudos sobre imigrantes e descendentes a partir do uso de depoimentos.

Em termos de grupos, os italianos são mais estudados, enquanto sírios e libaneses, judeus e japoneses comparecem em dissertações e teses em número similar aos alemães. Se computássemos pesquisas com fontes documentais, esses números seriam certamente diferentes, pois grupos de antiga imigração, como é o caso dos alemães, acumularam registros escritos ao longo do tempo. Como contraponto, veja-se o caso do estudo dos japoneses - um grupo de imigração recente, com muitos "pioneiros" capazes de fornecer testemunho direto -, que tem sido desenvolvido em diferentes instituições, das quais podem ser destacados programas de pós-graduação em história mais recentes. Além dos PPGHs da UFMT e UFPA, citados acima, também há pesquisas em duas novas instituições do estado do Paraná, estado que concentra o maior contingente de imigrantes japoneses depois de São Paulo: na Universidade Estadual de Londrina (UEL), cujo mestrado em história social é de 2007, e na Universidade Estadual de Maringá (UEM), cujo curso de pós-graduação em história iniciou em 2004. Nem sempre o número de pesquisas sobre determinado grupo tem relação direta com o número de imigrantes que o compóe. Segundo os censos demográficos do Rio Grande do Sul, por exemplo, referentes à primeira metade do século $\mathrm{XX}$, o número de estrangeiros residentes no estado e nascidos no Uruguai só é menor do que o dos nascidos na Itália. As pesquisas sobre os "uruguaios" daquele estado, entretanto, são relativamente recentes e escassas. As justificativas podem ser buscadas no funcionamento dos grupos étnicos: os modos de visibilização e identificação do grupo influenciam a percepção externa; em outras palavras, se um grupo tiver poucas manifestações identitárias publicizadas (festas, entidades, jornais), tenderá a despertar menos atenção sobre sua existência. ${ }^{13}$

Em termos de campos historiográficos, a metodologia da história oral direciona os estudos de imigração principalmente para a história cultural. Pesquisas sobre práticas alimentares de grupos imigrantes (Fernandes, 2010) constituem interpretações sobre cultura. Relações interétnicas, um assunto bastante recorrente em estudos de etnicidade, são "encontros culturais", que podem operar de forma amistosa, como se dá entre teuto-russos e "brasileiros"

13 "A proximidade cultural e geográfica foi um dos fatores apresentados para explicar a dificuldade em manter grupos ou organizações representativas dessa nacionalidade”, afirma Roja Fagúndez (2011, p. 127), referindo-se a uruguaios radicados na cidade de Pelotas. 
(luso-brasileiros ou caboclos) no oeste de Santa Catarina (Onghero, 2010), ${ }^{14}$ ou conflituosa, como quando o vigário de uma cidade do interior de Minas Gerais se recusa a sepultar uma senhora cristã ortodoxa de origem árabe na parte benta do cemitério local administrado pela Igreja católica. ${ }^{15}$ Por utilizarem uma de suas formulações teóricas mais caras, a de "representações", os estudos étnicos podem ser considerados um campo específico da história cultural. ${ }^{16}$ Nos extratos abaixo, vemos pesquisas acerca de imigrantes focando representações elaboradas sobre o grupo, no primeiro caso, e representações elaboradas pelo próprio grupo, no segundo:

A propaganda da [empresa] colonizadora simbolicamente representou os colonos japoneses como "nipo-bandeirantes" requisitando-os para um importante projeto político federal, como cidadãos, a fim de cultivarem a hevea em seu habitat nativo (Silva, 2004, p. 157; pesquisa sobre japoneses que se instalaram no norte do Mato Grosso).

[...] decidi realizar um estudo sistematizado dos elementos escolhidos pelos descendentes de judeus marroquinos para se auto-representarem, e para tentar entender como a identidade destes grupos é organizada a partir dos arranjos e representaçóes destes elementos (Lins, 2010, p. 17; pesquisa sobre imigrantes judeus que se instalaram na Amazônia).

As fontes orais também têm inegáveis contribuições para análises de cunho econômico, contribuindo para a relativização de algumas interpretaçóes consolidadas. O pesquisador espanhol Soutelo Vázquez (1998, p. 100) argumenta que a pesquisa qualitativa a partir dos documentos produzidos pelos próprios protagonistas superou a visão da imigração camponesa como uma reação inconsciente a mudanças sociais e apontou para uma estratégia

14 "Quando nós chegamos aqui, tinha caboclo morando. Nós não nos entendemos, mas ele mostrava, ensinava como e quando era pra plantar. Era assim, a mãe falava em alemão, mas ele falava em brasileiro (risos). Mas mostraram e se entenderam" (Onghero, 2010).

15 Este relato é um exemplo de "tradição oral" presente entre habitantes do local, pois o acontecimento remonta à primeira década do século (Lopes, 2010). A narrativa, ao apontar que o fato teria contribuído para a secularização do cemitério pela prefeitura, mostra também que grupo adventício não sofria uma discriminação generalizada.

16 Há interpretações que, na falta de uma problematização das representações, tomam por fato as "endoatribuições" dos entrevistados, concluindo, por exemplo, que a cultura do trabalho veio "na bagagem" dos imigrantes italianos (Pereira, 2010). 
racionalizada de mobilidade econômica e social ascendente por parte das famílias camponesas. Corroborando essas interpretações, Weber (2010) recolheu relatos de idas e vindas à América por membros de uma mesma família de imigrantes, em função de oportunidades de trabalho, e Érica Sarmiento da Silva (2006, p. 41) constatou que, mesmo quando rememoram os anos $1930 \mathrm{e}$ 1940, décadas da ditadura Vargas, nas quais houve diminuição do ingresso de espanhóis, os imigrantes galegos que se instalaram no Rio de Janeiro revelam uma imagem positiva do Brasil: "eles analisam a história desde a sua perspectiva, a de um estrangeiro num país com um mercado de trabalho carente de mão de obra e em um período de crescimento econômico". A autora também recolheu relatos de ascensão profissional para os que vinham com qualificações técnicas no pós-guerra (Sarmiento da Silva, 2006, p. 43).

Um estudo sobre mascates árabes, que se tornaram comerciantes lojistas na cidade de Rondonópolis, em Mato Grosso, entre as décadas de 1950 e 1970 (Rêgo, 2006), traz dados sobre especulação imobiliária, apropriação de terras, formação de novas classes proprietárias e empresariais. Entrevistas com descendentes de primeira e segunda geração de imigrantes italianos, por sua vez, permitem analisar sua contribuição para a formação de mão de obra numa sociedade recém-saída do regime escravocrata (Pereira, 2010). A utilização de depoimentos em pesquisas sobre imigrantes com enfoque econômico tem sido frequente em programas de pós-graduação interdisciplinares de "desenvolvimento" ou "integração" regional, como na Universidade de Blumenau (FURB) e na Universidade de Santa Cruz do Sul (UNISC), que possuem mestrado e doutorado em desenvolvimento regional.

Os exemplos de aspectos "econômicos" da imigração podem também ser enquadrados como "história do trabalho" e, para as discussões sobre identidade, merecem destaque as análises de relações interétnicas no universo produtivo, especialmente quando os proprietários pertencem a um grupo étnico específico ou, com menos frequência, quando os trabalhadores apresentam um perfil étnico diferenciado. Essas situações configuram contextos interétnicos e, quando acessíveis, as fontes orais revelam aspectos cotidianos nem sempre presentes em outros documentos. Maria José Ribeiro, ao estudar uma fábrica em Americana (SP) cujos proprietários foram sucessivamente ingleses e alemães, colheu relatos que indicam que uma mão de obra negra, identificada como "escrava", foi substituída, na transferência da empresa dos proprietários ingleses para os alemães, no início do século XX, por descendentes de imigrantes, principalmente italianos, muitos deles egressos de fazendas de 
café (Ribeiro, 2005, p. 114-18), permanecendo os cargos de direção em mãos de alemães, austríacos e suíços (p. 127).

Entre os teóricos que enfatizam a relação entre etnia e classe estão Wallerstein (2001, p. 66), para quem a "economia-mundo" acarretou, desde o início do capitalismo, uma grande correlação entre etnicidade e papel ocupacional/econômico ou "etnicização" da força de trabalho, e Fenton (2003, p. 228), que aponta que a relação entre classe e etnicidade tem sido abordada como um problema da modernidade capitalista tardia, que estimula o surgimento de "nichos étnicos" na economia. Um exemplo de lócus simultaneamente econômico e étnico pode ser o da concentração de árabes na Rua 25 de Março, na cidade de São Paulo, inicialmente em função de aluguéis mais baratos e da oportunidade de mascatear e fazer negócios na região, mas, também, como apontam pesquisas recentes com história oral, de ser um "local de referência identitária do grupo tanto externa como internamente” (Osman, 2009, p. 6).

Para a história política, as entrevistas com imigrantes que foram líderes de movimentos de resistência política ou simplesmente militantes de partidos operários no país de origem revelam um perfil específico de imigrante, o exilado político. Para as décadas de 1930 e 1940, no caso do Rio Grande do Sul, os exilados sobre os quais há mais estudos com história oral são os perseguidos pelo regime franquista após a vitória fascista na Espanha, como é o caso do estudo de Prochnow (2009). Também configura um exílio político a vinda de refugiados judeus que escaparam da perseguição nazista, como os que se instalaram em Rolândia - cuja história, em parte, foi narrada pela pesquisa com depoimentos (Soares, 2012). Imigrantes com atuação política que aguardam seu historiador são os militantes políticos poloneses, tanto os que resistiram à invasão nazista quanto os que permaneceram fiéis ao governo que se instalou em Londres, após a instalação do governo comunista no país; o historiador desse tema, contudo, dificilmente poderá contar com testemunhas diretas. ${ }^{17}$ Os que pesquisam os refugiados de perseguições políticas de regimes militares latino-americanos e seus filhos estão melhor posicionados no tempo com relação ao uso da fonte oral, como demonstra uma dissertação defendida na Universidade Federal de Pelotas cujo universo de entrevistados são "filhos de imigrantes uruguaios radicados em Pelotas, em especial [...] aqueles que foram trazidos pelas mãos de seus pais ainda crianças ou

17 Alguns estudos clássicos da imigração polonesa no Rio Grande do Sul, feitos por historiadores amadores, recolheram memórias sobre o assunto (ver Gardolinski, 1956). 
nasceram no Brasil nas últimas quatro décadas do século XX” (Roja Fagúndez, 2011, p. 10).

As pesquisas desenvolvidas no campo de estudos de “imigração" não são, portanto, exclusivas desse campo, podendo ser enquadradas não apenas nos macrocampos de história cultural, política, social e econômica, mas de história do trabalho, história agrária e outros subcampos que se desenvolveram mais recentemente, como história ambiental e das relações internacionais, como se pode ver nos dois exemplos que seguem: no PPGH da UFSC, o Laboratório de Imigração e Migração, constituído em 1994, converteu-se recentemente em Laboratório de Imigração, Migração e História Ambiental (LABIMHA) ${ }^{18}$; o LABIMI (Laboratório de Estudos de Imigração e Estrangeiros), sediado na UERJ (Universidade Estadual do Rio de Janeiro) produz estudos de imigração e de relações internacionais. É sabido que a vida humana não se desenvolve em compartimentos e que as classificações dos campos historiográficos são fruto da atividade científica, que analisa, decompõe em partes, para melhor interpretar. O cruzamento analítico entre campos diferentes pode, entretanto, prover o pesquisador de indispensáveis ferramentas heurísticas para interpretar algumas situações, o que é constatado na tese de Alexandre Fortes (2004), que recorreu à noção de etnicidade para melhor compreender as relações entre patróes e empregados e entre os próprios operários, cujas organizações trabalhistas possuíam caráter étnico.

Tradicional e amplo, e ainda com muito fôlego ${ }^{19}$, o campo de estudos de imigração tem incorporado novas metodologias de pesquisa, novas problemáticas e novas discussões conceituais, o que tem contribuído para sua renovação. As pesquisas sobre representações e identidades, grande parte delas estimulada pela metodologia da história oral, seguramente favoreceram a dinamização desse campo, cujo objeto de estudo tem sido, por outro lado, partilhado com outros campos, também dinâmicos, com seus congressos e linhas de pesquisa em programas de pós-graduação, o que está em sintonia com tempos que enfatizam a diversidade.

$18 \mathrm{Na}$ avaliação historiográfica de teses e dissertações vinculadas a esse núcleo de pesquisa (Oliveira; Klug, 2011), é recorrente a menção ao uso de metodologia de história oral.

19 O Simpósio de História da Imigração e Colonização, realizado na Unisinos e em outras instituições do Rio Grande do Sul, teve sua 16a edição em 2007 (Dreher; Tramontini, 2007). 


\section{Referências}

ALENCAR, Andrea da Silva Morais. Memórias e experiências de imigrantes espanhóis em Bueno Brandão - MG 1960-1990. 128 p. Tese (Doutorado em História) - PUC-SP, São Paulo, SP, 2009.

BOURDIEU, Pierre. A distinção: crítica social do julgamento. Porto Alegre: Zouk, 2007.

DI GREGORIO, Maria de Fátima Araújo. Memória coletiva: estratégias de preservação da identidade cultural dos imigrantes italianos em Itiruçu-BA, 1950-2000. 182 p. Dissertação (Mestrado em Memória Social e Documento) - UNIRIO, Rio de Janeiro, RJ, 2001.

DOMINGUES, Luis Estebam. Imigração argentina em São Paulo 1970-1983: ressignificando identidades. 252 p. Dissertação (Mestrado em História) - PUC-SP, São Paulo, SP, 2004.

DREHER, Martin N., TRAMONTINI, Marcos J. (Org.). Leituras e interpretações da imigração na América Latina. Anais do XVI Simpósio de História da Imigração e Colonização. São Leopoldo: Oikos, 2007. CD-ROM.

FENTON, Steve. Etnicidade. Lisboa: Instituto Piaget, 2003.

FERNANDES, Maria Cristina Rodrigues. As aventuras do gosto: o restaurante Al Manzul de Cuiabá como expressão da culinária árabe (1991-2008). 110 p. Dissertação (Mestrado em História) - UFPR, Curitiba, PR, 2010.

FORTES, Alexandre. Nós do Quarto Distrito: a classe trabalhadora porto-alegrense e a era Vargas. Caxias do Sul: Educs; Rio de Janeiro: Garamond, 2004.

GARDOLINSKI, E. Imigração e colonização polonesa. In: BECKER, K. (Org.). Enciclopédia Rio-Grandense. Canoas: Regional, 1956. v. 5, p. 1-104.

GATTAZ, André Castanheira. História oral da imigração libanesa para o Brasil - 1880 a 2000. Tese (Doutorado em História Social) - USP, São Paulo, SP, 2001.

GUEDES, Luana Sullivan B. Memórias em exílio, identidades em trânsito: angolanos no Pará (1975-2004). 168 p. Dissertação (Mestrado em História) - PUC-SP, São Paulo, SP, 2005.

HALBWACHS, Maurice. A memória coletiva. São Paulo: Centauro, 2006.

ISHIZU, Tatsuo. Imigração e ocupação na fronteira do Tapajós: os japoneses em Monte Alegre - 1926-1962. 135 p. Dissertação (Mestrado em História) - UFPA, Belém, PA, 2007.

LINS, Wagner. A mão e a luva: judeus marroquinos em Israel e na Amazônia - similaridades e diferenças na construção das identidades étnicas. 237 p. Tese (Doutorado em Língua Hebraica, Literatura e Cultura Judaica) - USP, São Paulo, SP, 2010. 
LOPES, Leandro Aparecido. Cultura, identidade e memória: a colônia síria e libanesa e a igreja ortodoxa em Guaxupé. In: ENCONTRO NACIONAL DE HISTÓRIA ORAL, 10, 2010, Pernambuco. Anais eletrônicos. Associação Brasileira de História Oral, 2010. 13 p. Disponível em: <http://www.encontro2010.historiaoral.org.br/resources/ anais/2/1266371209_ARQUIVO_LeandroApLopes.pdf $>$. Acesso em: 14 maio 2013.

MORETTO, Samira P.; NODARI, Eunice S. O meio ambiente como tema da história. In: FLORES, Maria Bernardete R.; BRANCHER, Ana Lice (Org.). Historiografia: 35 anos. [Florianópolis]: Letras Contemporâneas, 2011. p. 93-109.

NASCIMENTO, José do. Santa Paulina, reconquista e territorialidade: uma história em Nova Trento-SC. Dissertação (Mestrado em História) - UFSC, Florianópolis, SC, 2006.

OLIVEIRA, Eveli S. D’Avila; KLUG, João. Imigração e cultura étnica em Santa Catarina. In: FLORES, Maria Bernardete R.; BRANCHER, Ana Lice (Org.). Historiografia: 35 anos. [Florianópolis]: Letras Contemporâneas, 2011.p. 79-92.

ONGHERO, André Luiz. Aprendendo a viver em novas terras: relações entre o grupo teuto-russo, os luso-brasileiros e os teuto-brasileiros em São Carlos-SC. In: ENCONTRO NACIONAL DE HISTÓRIA ORAL, 10, 2010, Pernambuco. Anais eletrônicos. Associação Brasileira de História Oral, 2010. 17 p. Disponível em: <http://www.encontro2010. historiaoral.org.br/resources/anais/2/1269195158_ARQUIVO_andre_luiz_onghero_ artigoabho2010.pdf >. Acesso em: 14 maio 2013.

OSMAN, Samira Adel. Mascates árabes em São Paulo: concentração urbana e inserção econômica. Revista Cordis: Revista Eletrônica de História Social da Cidade, São Paulo, n. 2, jan./jun. 2009. 17 p.

PEREIRA, Lígia Maria Leite. Imigração italiana e desenvolvimento em Minas Gerais. In: ENCONTRO NACIONAL DE HISTÓRIA ORAL, 10, 2010, Pernambuco. Anais eletrônicos. Associação Brasileira de História Oral, 2010. 13 p. Disponível em: <http:// www.encontro2010.historiaoral.org.br/resources/anais/2/1269892337_ARQUIVO_ ABHO2010-ImigracaoitalianaedesenvolvimentoemMinasGerais-LigiaMariaLeitePereira. pdf >. Acesso em: 14 maio 2013.

PEREIRA, Syrléa Marques. Entre histórias, fotografias e objetos: imigração italiana e memórias de mulheres. 280 p. Tese (Doutorado em História) -UFF, Niterói, RJ, 2008.

PERES, E. P. A inexistência da terra firme: a imigração galega em São Paulo, 1946-1964. São Paulo: Editora da Universidade de São Paulo/FAPESP/Imprensa Oficial do Estado. 2003.

POUTIGNAT, P.; STREIFF-FENART, J. Teorias da etnicidade. São Paulo: Editora da UNESP, 1998.

PROCHNOW, Lucas N. Memórias, narrativas e história: a imigração espanhola recente em Porto Alegre. 157 p. Dissertação (Mestrado em História) - PUCRS, Porto Alegre, RS, 2009. 
RÊGO, Marildes Ferreira do. Memória da imigração de sírios e libaneses em RondonópolisMT. Dissertação (Mestrado em História) - UFMT, Cuiabá, MT, 2006.

RIBEIRO, Maria José Ferreira de Araujo. Memória, imigração e educação - Fábrica de tecidos Carioba: uma vila industrial paulista no início do século XX. 200 p. Tese (Doutorado em Educação) - UNICAMP, Campinas, SP, 2005.

ROJA FAGÚNDEZ, Ariel Salvador. "Ni de acá, ni de Allá": memória e identidade de filhos de uruguaios residentes em Pelotas/RS. 136 p. Dissertação (Mestrado em Ciências Sociais) - UFPEL, Pelotas, RS, 2011.

SARMIENTO DA SILVA, Érica. Galegos no Rio de Janeiro (1850-1970). Tese (Doutorado) - Facultade de Xeografía e Historia, USC, Santiago de Compostela, Espanha, 2006.

SAYAD, Abdelmalek. A imigração: ou os paradoxos da alteridade. São Paulo: EDUSP, 1998. SILVA, Aldina Cássia Fernandes da. Nas trilhas da memória: uma colônia japonesa no norte de Mato Grosso (Gleba Rio Ferro, 1950-1970). 202 p. Dissertação (Mestrado em História) - UFMT, Cuiabá, MT, 2004.

SILVA, Luzia Maria de Oliveira e. A trajetória politica de Whady José Nassif, prefeito de Uberaba no periodo entre 1937 e 1943. 154 p. Dissertação (Mestrado em História) - UFU, Uberlândia, MG, 2006.

SOARES, Marco Antonio Neves. Da Alemanha aos trópicos: identidades judaicas na terra vermelha (1933-2003). Londrina: Editora da UEL, 2012.

SOUTELO VÁZQUEZ, R. Memoria oral e identidade étnica da inmigración española a latinoamérica no século XX: os galegos en Brasil, 1880-1970. Estudios Migratorios, Santiago de Compostela, n. 6, p. 97-124, dez. 1998.

THOEN, Carla Fernanda C. Representaçóes sobre etnicidade e cultura escolar nas antigas colônias de imigração italiana do nordeste do Rio Grande do Sul (1905-1950). 154 p. Dissertação (Mestrado em Educação) - UCS, Caxias do Sul, RS, 2011.

WALLERSTEIN, Immanuel. Capitalismo histórico e civilização capitalista. Rio de janeiro: Contraponto, 2001.

WAWZYNIAK, Sidinalva M. S. História de estrangeiro: passos e traços de imigrantes japoneses (1908-1970). 260 p. Tese (Doutorado em História) - UFPR, Curitiba, PR, 2004.

WEBER, Regina. Galegos no sul do Brasil: alternativas na América. Anos 90, Porto Alegre, v. 17, n. 31, p. 78-108, jul. 2010.

WENCZENOVICZ, Thais Janaina. Luto e silêncio: doença e morte na área de colonização polonesa no Rio Grande do Sul (1910-1945). 279 p. Tese (Doutorado em História) PUCRS, Porto Alegre, RS, 2007. 


\title{
Páginas institucionais
}

COORDENAÇÃO DE APERFEIÇOAMENTO DE PESSOAL DE NÍVEL SUPERIOR (CAPES). Banco de Teses. Disponível em: <http://capesdw.capes.gov.br/ capesdw/>. Acesso em: 2 jan. 2013.

COORDENAÇÃO DE APERFEIÇOAMENTO DE PESSOAL DE NÍVEL SUPERIOR (CAPES). Caderno de indicadores. Disponível em: <http://conteudoweb. capes.gov.br/conteudoweb/CadernoAvaliacaoServlet>. Acesso em: 18 dez. 2012.

UNISINOS. Programa de Pós-Graduação em História. Disponível em: <http://www. unisinos.br/mestrado-e-doutorado/historia/>. Acesso em: 22 dez. 2012.

UNIVERSIDADE ESTADUAL DO RIO DE JANEIRO. Laboratório de Estudos de Imigração e Estrangeiros (LABIMI). Disponível em: <http://www.labimi.uerj.br/>. Acesso em: 5 jan. 2012.

UNIVERSIDADE FEDERAL DE MATO GROSSO. Programa de Pós-Graduação em História. Disponível em: <http://www.ppghis.com/site/>. Acesso em: 3 jan. 2013.

UNIVERSIDADE FEDERAL DE SANTA CATARINA. Laboratório de Imigração, Migração e História Ambiental (LABIMHA). Disponível em: <http://www.labimha.ufsc. br/>. Acesso em: 3 jan. 2013.

Resumo: Este artigo apresenta, após uma problematização da categoria “imigrante”, algumas interpretações resultantes da observação de estudos acadêmicos sobre imigração que se utilizaram da metodologia da história oral nas últimas décadas. Essa investigação indica uma diversificação dos grupos pesquisados e das áreas geográficas do país onde eles são encontrados, o emprego de novos aportes teóricos - com destaque para teorias de identidade e etnicidade - e a presença de novas instituições universitárias e diversos campos historiográficos no desenvolvimento de tais estudos.

Palavras-chave: imigração, história oral, identidade étnica, historiografia.

\section{Studies on immigrants and oral sources: identity and diversity}

\begin{abstract}
This article presents, after questioning the "immigrant" category, a few interpretations as result of the observation of academic studies on immigration in which the Oral History methodology was used in the last decades. This investigation indicates diversification of the groups studied and the geographic areas of the country where they are found, the use of new theoretical approaches, highlighting identity and ethnicity theories, as well as the presence of new universities and several historiographic fields where such studies are developed.
\end{abstract}

Keywords: immigration, oral history, ethnic identity, historiography.

Recebido em 07/01/2013

Aprovado em 15/04/2013 